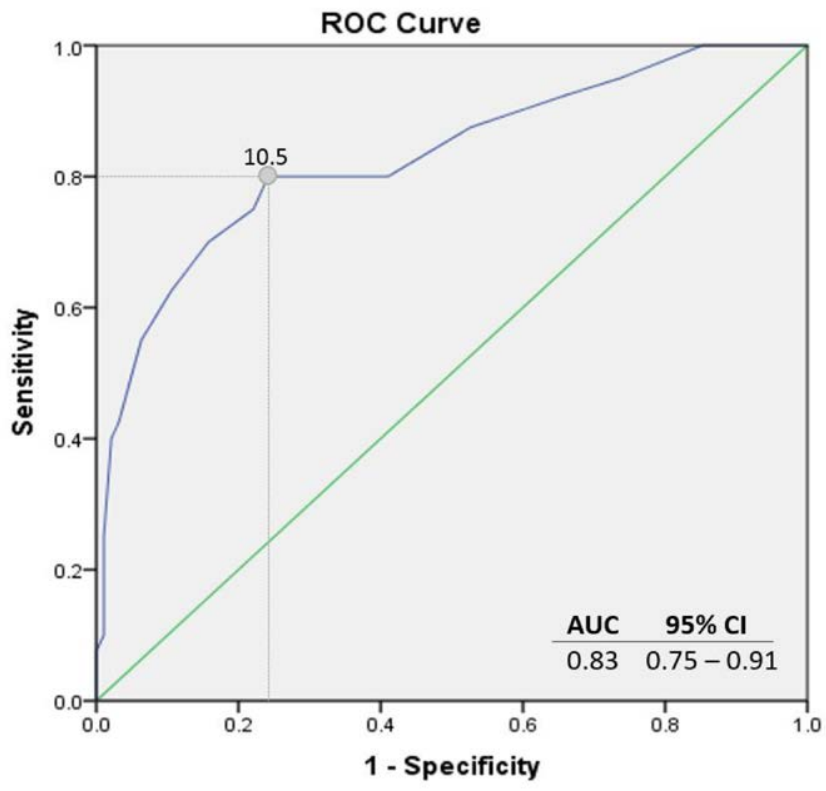

Figure 1. ROC curve depicting sensitivity and (1-) specificity. The AUC was $0.83(95.0 \% \mathrm{Cl}$ $0.75-0.91$ ) with an optimal cut-off value of 10.5 (sensitivity $80.0 \%$, specificity $75.8 \%$ ).

Disclosure of Interests: None declared DOI: 10.1136/annrheumdis-2021-eular.2466

\section{AB0376 LEVEL OF DIAGNOSTIC AND THERAPEUTIC KNOWLEDGE, SKILLS AND COMPETENCIES IN GIANT CELL ARTERITIS AMONG EMERGENCY MEDICAL STAFF}

C. Guillén-Astete $^{1}$, I. Perea-Fuentes ${ }^{2}$, L. Ayala-Terrados ${ }^{2}$, N. García-Montes ${ }^{3}$. ${ }^{1}$ Hospital Ramón y Cajal, Rheumatology, MADRID, Spain; ${ }^{2}$ CEU San Pablo, Medicine, Madrid, Spain; ${ }^{3}$ Hospital Ramón y Cajal, Emergency, Madrid, Spain

Background: Giant cell arteritis (GCA) is the most frequently diagnosed vasculitis in Spain. The highest incidence recorded in the country is 17 new cases per 100,000 inhabitants/year. Its delayed diagnosis exposes the patient to an increased risk of multiple ischaemic complications. Among them, vision loss has been reported in up to 1 in 6 cases. Most of these patients, according to unpublished local observations, presented with headache, visual disturbances or polymyalgic symptoms to an emergency department facility and were not correctly or prompted diagnosed.

Objectives: To determine the level of knowledge, skills and diagnostic and therapeutic competencies of the medical staff of multiple emergency departments in our city in regard to giant cell arteritis.

Methods: We designed an observational study based on a single survey carried out between February and March 2020 to medical staff from 12 emergency departments in the city of Madrid. Four private and eight public emergency departments were deliberately included. The selection of the surveyed staff was randomly selected to reach $50 \%$ of the total number of physicians in each department. A total of 229 surveys were distributed by e-mail. A total of 125 physicians responded (final response rate $54.5 \%$ ). Twenty-two physicians $(9.2 \%)$ did not respond to the request and the rest declined to participate, although they responded to the demographic section (35.8\%).

The survey included the following sections: respondent profile, knowledge of epidemiological aspects, identification of clinical manifestations, diagnostic and therapeutic skills, and educational interest.

Results: Forty respondents (33.6\%) worked in a privately managed emergency department and $79(66.4 \%)$ in a public centre. The mean age of respondents was 37.3 SD 5.9 years, and the proportion of women was $62.4 \%$. Mean length of service was 3.4 SD 1.2 years among physicians in private emergency departments and 5.7 SD 2.3 in a public management unit. Sixty-four respondents $(53.7 \%)$ were specialists in Family and Community Medicine, and 46 $(38.6 \%)$ in internal medicine. No significant differences in demographic characteristics were identified between respondents who agreed to participate and those who declined.
In regard to epidemiological knowledge, $50.6 \%$ of respondents were unable to identify the age group at highest risk of GCA, $32.7 \%$ did not recognise its predominance in the female sex, and $26 \%$ did not know the approximate incidence of the disease.

In terms of diagnostic suspicion, $46.2 \%$ of respondents were able to identify at least five clinical manifestations of the disease. Elevated ESR, CRP and the presence of anaemia were recognised as positive analytical data by $98.3 \%$, $85.7 \%$ and $57.7 \%$ of respondents, respectively. Ultrasonography of temporal arteries was identified by $97.5 \%$ of respondents as a useful diagnostic technique. One hundred and two respondents $(81.6 \%)$ indicated that they had not suspected GCA in the last month. In the last year, 34 respondents $(27.2 \%)$ reported having diagnosed the disease on at least one occasion. Regarding treatment, in cases of absence of ischaemic lesion $85.7 \%$ indicated suboptimal corticosteroid therapy guidelines, however, $63.0 \%$ of the respondents self-rated their therapeutic skills as very good or excellent.

Finally, $88.2 \%$ of respondents expressed interest in participating in training programmes in diagnosis and treatment of GCA.

Conclusion: There are important areas for improvement in knowledge, diagnostic skills and therapeutic competencies among emergency physicians in relation to the suspicion and management of GCA.

Disclosure of Interests: None declared

DOI: 10.1136/annrheumdis-2021-eular.2815

\section{AB0377 19 CLINICAL REVIEW OF 19 CASES WITH IDIOPATHIC AORTITIS - A SINGLE CENTRE STUDY}

M. J. Villar ${ }^{1}$, S. Sangle ${ }^{2}$, D. D'cruz ${ }^{2} .{ }^{1}$ Clinica Alemana, Reumatolog ía, Vitacura, Chile; ${ }^{2}$ Guys and St Thomas' Hospital NHS Foundation Trust, Louise Coote Lupus Unit, London, United Kingdom

Background: Aortitis is a group of disorders leading to inflammation in the aorta. When aortitis has no clinical evidence of systemic vasculitis, it is called idiopathic aortitis or clinically isolated aortitis (CIA).

There is no consensus on the management of CIA.

Objectives: Our purpose is to describe our cohort of patients with $\mathrm{CIA}$ and their response to treatment.

Methods: This is a retrospective analysis of 19 patients with $\mathrm{CIA}$. All records of patients with CIA were analyzed and demographic variables, comorbidities, symptoms, images, histology, treatment

received, outcome and mortality were recorded. The description of quantitative variables was made using the median and the interquartile range (IQR).

Results: Nineteen patients were analyzed. Diagnosis was made by imaging in $18(94.7 \%)$, one patient was diagnosed by histology after aortic root surgery. Patient characteristics are detailed in Table 1.

The median duration of follow- up was 38 months (IQR 43). Seven patients (36.8\%) had constitutional symptoms including fever, weight loss, sweats and fatigue. $4(21.05 \%)$ presented with back or abdominal pain for a mean duration of 3 months (SD 0.81 ) before the diagnosis. In $8(42.1 \%)$ patients the diagnosis was made incidentally.

All patients had negative treponema, hepatitis $\mathrm{B}$, hepatitis $\mathrm{C}$ and Human Immunodeficiency Virus (HIV) serology.

All patients had negative autoimmune serology included ANCA. Interestingly $4(21.05 \%)$ had positive lupus anticoagulant without other manifestation of antiphospholipid syndrome.

The type of aortic involvement was aortitis in 10 patients $(52.6 \%)$, inflammatory aneurysm in $8(42.1 \%)$ and dissection in $1(5.2 \%)$.

Seven (36.8\%) patients had thoracic and abdominal aorta involvement, 6 (31.5\%) only thoracic aorta and 6 (31.5\%) only abdominal aorta.

Aortic histology was obtained in 5 patients, 2 had necrotizing arteritis with giant cell pattern and 2 had lymphoplasmacytic pattern. Temporal artery biopsy was done in one patient and the result was negative for GCA.

All patients received corticosteroids as a remission inducing agent, 12 $(63.1 \%)$ received methotrexate and $2(10.5 \%)$ mycophenolate. 2 patients died $(10.5 \%)$.

The median prednisone dose at the beginning was $20 \mathrm{mg}$ (IQR 20) and at remission was $5 \mathrm{mg}$ (IQR 20). 41.6\% (5/12) of patients treated with steroids plus methotrexate were able to stop steroids without reactivation over a median follow-up time of 23.5 months (IQR 31). (Table 2.)

Details of treatment, ESR and CRP pre and post treatment is shown in Figure 1.

Seven patients $(36.8 \%)$ had follow-up imaging, none of them showed active inflammation, new aneurysm, dissection or disease progression.

Conclusion: Treatment of isolated aortitis with steroids and methotrexate was effective resulting in clinical and laboratory improvement and allowed cessation or decrease in steroids to $5 \mathrm{mg}$ or less in $83 \%$ of patients. This therapeutic approach may be useful in patients with $\mathrm{CIA}$. 
Table 1. Characteristic of the patients.

\begin{tabular}{|l|l|}
\hline No Patients & 19 \\
\hline Female & $6(31.5 \%)$ \\
\hline Male & $13(68.4 \%)$ \\
\hline Age median & $64($ (IQR18) \\
\hline Ethnicity & $4(21.05 \%)$ \\
\hline \multicolumn{1}{|c|}{ Caucksian } & $15(78.9 \%)$ \\
\hline Comorbidities & \\
\hline Diabetes mellitus type 2 & \\
\hline Hypertension & $2(10.5 \%)$ \\
\hline Obesity & $12(63.1 \%)$ \\
\hline Hypercholesterolemia & $5(26.3 \%)$ \\
\hline Smoker & $9(47.3 \%)$ \\
\hline & $6(31.5 \%)$ \\
\hline $\begin{array}{l}\text { No (\%) patients with prednisone } \leq 5 \text { mg at end of } \\
\text { follow-up according to treatment received }\end{array}$ & \\
\hline Only steroids (5) & \\
\hline Steroids + methotrexate (12) & $1(20 \%)$ \\
\hline Steroids+ mycophenolate (2) & $10(83.3 \%)$ \\
\hline & $1(50 \%)$ \\
\hline
\end{tabular}

\section{REFERENCES:}

[1] Cinar, I., Wang, H., \& Stone, J. R. (2017). Clinically isolated aortitis: pitfalls, progress, and possibilities. Cardiovascular Pathology, 29, 23-32.

Disclosure of Interests: None declared

Figure 1

\section{Changes in median ESR and CRP in follow-up}

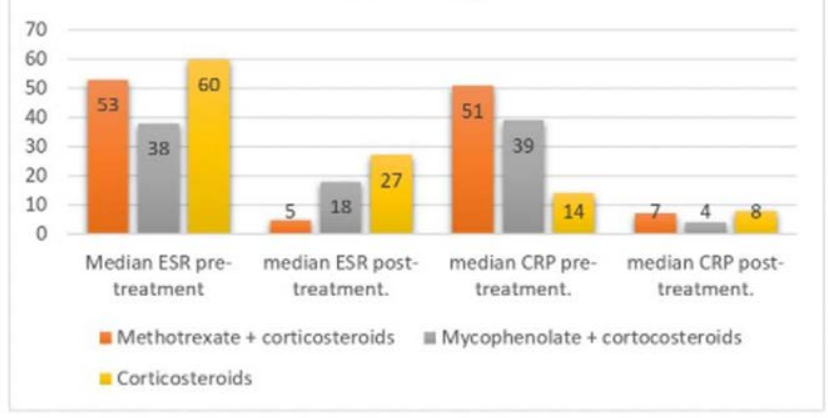

DOI: 10.1136/annrheumdis-2021-eular.3373

\begin{tabular}{l|l}
\hline AB0378 & UTILITY AND ACCURACY OF SOUTHEND \\
& PRETEST PROBABILITY SCORE IN GCA FAST- \\
& TRACK CLINIC: ANALYSIS IN 261 CONSECUTIVE \\
& PATIENTS
\end{tabular}

J. Ortega ${ }^{1}$, I. Monjo ${ }^{2}$, E. Fernández-Fernández ${ }^{2}$, E. De Miguel ${ }^{1,2} .{ }^{1}$ Universidad Autónoma Madrid, Rheumatology, Madrid, Spain; ${ }^{2}$ Universitary Hospital La Paz, Rheumatology, Madrid, Spain

Background: Strategies for early diagnosis of Giant Cell Arteritis (GCA) have been implemented in the last decade in order to reduce the occurrence of blindness, ischemic events and other manifestations of the disease. The Southend pretest probability score (SPTPS) ${ }^{1}$ seem to be useful in stratifying and select the referral patients sent to the GCA fast-track clinics.

Objectives: The aim of this study was to test the validity and utility of this score in our patients.

Methods: Retrospective available data records of all the patients referred to our GCA fast-track clinic in the last three years were collected. The clinical and laboratory features at referral were evaluated, and the SPTPS was generated. All patients had ultrasound of cranial and large vessel examination (axillary, subclavian and carotid arteries). GCA diagnosis was confirmed by the doctor after at least six months of follow-up. Quartile frequencies, ROC curves and accuracy of the SPTPS was calculated.

Results: 261 patients (180 females) with suspicions of GCA were evaluated in our fast-track clinic. Mean age $( \pm S D)$ was $76 \pm 9.2$ years, and C-reactive protein $75.7 \pm 68.6 \mathrm{mg} / \mathrm{l}$. The time since the first symptoms was less of 6 , $6-12,12-24$ or $>24$ weeks in $37.5 \%, 19.9,12.3$ and 15.7 respectively. Mean SPTPS was $11.4 \pm 4.4$, with values of $9.1 \pm 3.2$ and $12.9 \pm 4.4$. The area under the ROC curve was 0.761 (95\% confidence interval: $0.703-0.819)$. PTPS overall showed a $50^{\text {th }}$ percentile score of 11 and a 75 th percentile score of
14. We, therefore, classified "Low Risk" (LR) as SPTPS <11, "Intermediate Risk" (IR) 11-14 and "High Risk" (HR) >14. Of 261 referrals, 156 had GCA with cases categorised as LR (119), IR (91) and HR (51). HR score showed a specificity of $96.2 \%$ and in IR the specificity ranged between 86.7 and $94.3 \%$ (Table 1). Score below 7 appears in 29 cases with only 8 cases of GCA with a probability of GCA $<5 \%$, more of these cases was associated a large vessel vasculitis: 3 cranial arteritis (CA), 4 large vessel vasculitis (LVV) and 1 mixed pattern (MP). LR score included 72 of the $105(68.6 \%)$ non-GCA cases but 47 of 156 (30.1\%) GCA patients (20 CA, 11 LVV and 16 MP). IR risk score included $26(24.8 \%)$ of the non-GCA cases and $65(41.7 \%)$ of GCA patients (31 CA, 13 LVV and $21 \mathrm{MP}$ ). Finally HR score had only 7 non-GCA cases and $44(28.2 \%)$ patients with GCA (20 CA, 11 LVV and 13 MP). Mean score in cranial forms was $13.1 \pm 4.5$ and in large vessel vasculitis $12.8 \pm 5.0$ $(p=0.807)$.

Table 1. Sensitivity and Specificity of SPTPS at different cut-off points

\begin{tabular}{lcc}
\hline Cut-off point & Sensitivity & 1 -Specificity \\
\hline 2 & 1.000 & 1.000 \\
3.5 & 0.994 & 0.971 \\
4.5 & 0.987 & 0.943 \\
5.5 & 0.987 & 0.876 \\
6.5 & 0.949 & 0.790 \\
7.5 & 0.897 & 0.676 \\
8.5 & 0.846 & 0.476 \\
9.5 & 0.750 & 0.362 \\
10.5 & 0.679 & 0.248 \\
11.5 & 0.538 & 0.133 \\
12.5 & 0.449 & 0.086 \\
13.5 & 0.353 & 0.057 \\
14.5 & 0.218 & 0.038 \\
15.5 & 0.147 & 0.019 \\
16.5 & 0.128 & 0.019 \\
17.5 & 0.077 & 0.010 \\
19 & 0.038 & 0,000 \\
20.5 & 0.032 & 0,000 \\
21.5 & 0.019 & 0,000 \\
22.5 & 0.013 & 0,000 \\
24 & 0.000 & 0,000 \\
\hline
\end{tabular}

Conclusion: The SPTPS is helpful to stratified patients sent to the fast-track clinic. Scores below of 7 points has a very low probability to have GCA. The diagnostic probability increases directly with the score. There were minor differences without statistical significance between cranial or large vessel vasculitis patterns in the score.

\section{REFERENCES:}

[1] Sebastian A, Tomelleri A, Kayani A, Prieto-Pena D, Ranasinghe C, Dasgupta B. Probability-based algorithm using ultrasound and additional tests for suspected GCA in a fast-track clinic. RMD Open. 2020 Sep;6(3):e001297. doi: 10.1136/rmdopen-2020-001297. PMID: 32994361 PMCID: PMC7547539.

Disclosure of Interests: Javier Ortega: None declared, Irene Monjo Speakers bureau: Roche, Novartis, UCB, Gedeon Richter, Consultant of: Roche, Elisa Fernández-Fernández: None declared, Eugenio de Miguel Speakers bureau: AbbVie, Novartis, Pfizer, MSD, BMS, UCB, Roche, Grunental, Janssen, Sanofi., Paid instructor for: Janssen, Novartis, Roche, Consultant of: AbbVie, Novartis, Pfizer, Galapagos, Grant/research support from: Abbvie, Novartis, Pfizer

DOI: 10.1136/annrheumdis-2021-eular.3385

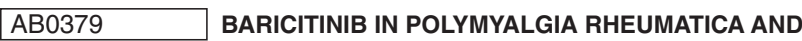 GIANT CELL ARTERITIS: REPORT OF SIX CASES}

D. Camellino ${ }^{1}$, C. Dejaco ${ }^{2,3}$, A. Giusti ${ }^{1}$, F. Martini ${ }^{4}$, R. Cosso ${ }^{5}$, G. Girasole ${ }^{1}$, G. Bianchi' . ' Local Health Trust 3, Genoa, Division of Rheumatology, Department of Medical Specialties, Genoa, Italy; ${ }^{2}$ Medical University Graz, Department of Rheumatology, Graz, Austria; ${ }^{3}$ Hospital of Bruneck (ASAASABES), Department of Rheumatology, Bruneck, Italy; ${ }^{4}$ Local Health Trust 1, Medical Department, Sanremo, Italy; ${ }^{5}$ Local Health Trust, 3, Medical Department, Genoa, Italy

Background: Glucocorticoids (GC) are the cornerstone of the treatment of polymyalgia rheumatica (PMR) and giant cell arteritis (GCA), but they are associated with several adverse events (AEs). Moreover, a considerable proportion of patients relapse during $\mathrm{GC}$ tapering.

Objectives: To describe the efficacy and safety of the JAK-inhibitor baricitinib (BARI) in a group of patients with PMR and/or GCA. 